\title{
Characterization of a planar L-glutamate amperometric biosensor immobilized with a photo-crosslinkable polymer membrane
}

\author{
Ku-Shang Chang ${ }^{a, b, * *}$, Chen-Kai Chang ${ }^{a, c}$, Su-Fen Chou ${ }^{a, d}$, \\ Hsei-Chen Han ${ }^{\text {a }}$, Chien-Yuan Chen ${ }^{\mathrm{a}, *}$ \\ ${ }^{a}$ Department of Biochemical Science and Technology, Graduate Institute of Microbiology and Biochemistry, National Taiwan University, \\ No. 1, Sec. 4, Roosevelt Road, Taipei 106, Taiwan \\ ${ }^{\mathrm{b}}$ Department of Food Science, Graduate Institute of Biotechnology, Yuanpei University of Science and Technology, Hsinchu, Taiwan \\ ${ }^{\mathrm{c}}$ Department of Food Science and Technology, Chia Nan University of Pharmacy and Science, Tainan, Taiwan \\ ${ }^{\mathrm{d}}$ Department of Biotechnology, Chia Nan University of Pharmacy and Science, Tainan, Taiwan \\ Received 1 January 2006; received in revised form 19 May 2006; accepted 19 May 2006 \\ Available online 5 July 2006
}

\begin{abstract}
A photo-crosslinkable polymer mixed with bovine serum albumin was adapted to fabricate an amperometric planar L-glutamate biosensor. The characteristics of this amperometric biosensor during aging of the membrane, its reproducibility and the effects of storage conditions on the long-term stability of the biosensor were studied. The steady-state method (R.S.D. $=3.69 \%$ ) was more appropriate than the kinetic method (R.S.D. $=7.70 \%$ ) for measuring the concentration monosodium glutamate. The L-glutamate amperometric biosensor exhibited remarkable longterm stability (150 days) when maintained in a dry dark state. Most of the functional characteristics of the biosensor were restored within 5 min (wet-up times) of repeated wetting and drying. The long-term stability and short wet-up times of the electrode suggests its suitability for use in the design of real time or flow injection biosensors.
\end{abstract}

(C) 2006 Elsevier B.V. All rights reserved.

Keywords: PVA-SbQ; Planar electrode; Biosensor; Shelf-life; L-Glutamate

\section{Introduction}

Recent trends have put increased emphasis on the development of small, portable and battery-operated instruments suited for use in on-site de-centralized bio-medical and industrial sensing systems [1-3]. Electrochemical instruments may be the ideal solution for this purpose, because of their potential to be compact, inexpensive, rugged, and versatile [4]. Planar electrodes may be well suited for use in these systems because of their advantages of being inexpensive and easily mass-produced [5-8]. Over the past few years, planar sensors have been brought into use for measuring blood glucose and electrolytes, and have also been introduced in portable cartridge-based critical-

\footnotetext{
* Corresponding author. Tel.: +886 223630231 x3256; fax: +8862 23661696

** Corresponding author. Tel.: +8863 5381183x8483; fax: +88635385353.

E-mail addresses: tommy.first@msa.hinet.net (K.-S. Chang), chenyuan@ntu.edu.tw (C.-Y. Chen).
}

care systems. However, the shorter shelf-life of planar sensors compared to traditional three-dimensional sensors necessitates the search for methods to improve stability [9-11]. Enzyme immobilization is a critical technique for the fabrication of a long-term stable planar electrode which is either reuseable or used in continuous analysis. A photo-crosslinkable polymer PVA-SbQ has been reported to be suitable for fabrication of a stable enzyme membrane (about $1 \mu \mathrm{m}$ thick) on a planar electrode [12]. PVA-SbQ is a polyvinyl alcohol bearing a styrylpyridinium (SbQ) residue as its photosensitive group. The cross-linking of the polymer is performed using UV radiation to produce cyclodimerization of the styrylpyridinium groups (Fig. 1A) [13-15]. A photosensitive polymer which contains $\mathrm{SbQ}$ is suitable for immobilizing enzymes because of its good water solubility which is needed to entrap enzyme homogeneously, and its ability to immobilize enzymes in the polymer using photolithography techniques [16]. Because of these characteristics it can be adapted to mass production using ordinary screen-printing or semiconductor-fabrication processes on a pla- 


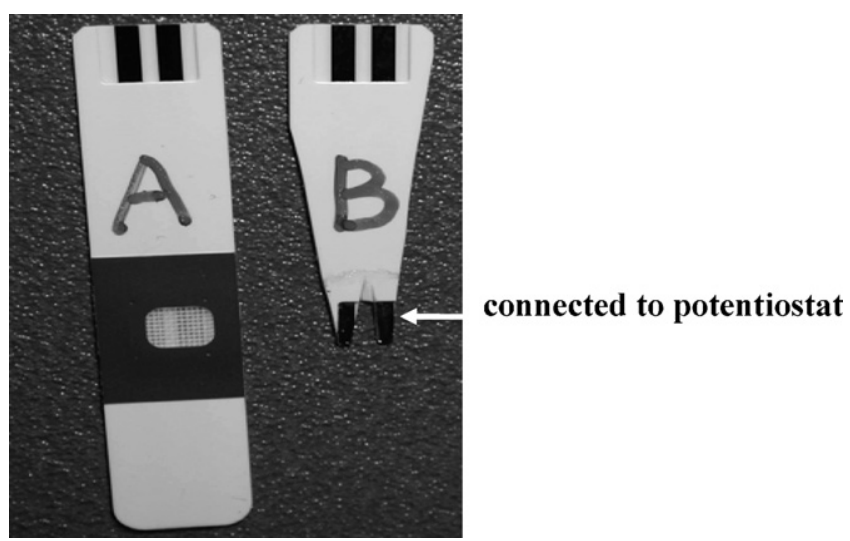

Fig. 1. (A) The palladium strip of the commercial electrode. (B) The strip after modification for use in this work.

nar electrode [17-20]. Nevertheless, no data is available on the change in the properties of the PVA-SbQ membrane soon after fabrication, and the membrane has been reported to be unstable before it swells thoroughly [21].

This study examined the characteristics of a planar electrode fabricated by the immobilization of L-glutamate oxidase in a photo-crosslinkable polymer membrane. The characteristics of this enzyme electrode were studied, including optimized enzyme immobilization conditions, the change in the properties of the PVA-SbQ membrane soon after fabrication, reproducibility and the effect of storage conditions on the long-term stability. The measurement range and stability of the proposed planar amperometric L-glutamate biosensor were also compared with other recently reported measurement systems [22-28].

\section{Experimental}

\subsection{Reagents}

Bovine serum albumin (BSA), monosodium glutamate (MSG) and glutaraldehyde were purchased from Sigma Chemical Co. (St. Louis, MO, USA). Fluorad FC-430 was obtained from 3 M Co. (St. Paul, MN, USA). PVA-SbQ (degree of polymerization 1700 , degree of saponification $87 \%$ ) was obtained from Toyo Gosei Kogyo Chemical (Tokyo, Japan).

The enzyme L-GLOx (EC 1.4.3.11) was produced in this laboratory from Streptomyces sp. NTU 3304 [29]. The palladium strip electrode was obtained from Boehringer-Mannheim (Mannheim, Germany). The buffer used for assay was $100 \mathrm{mM}$ phosphate buffer saline (PBS) and was prepared by mixing a stock standard solution of $\mathrm{K}_{2} \mathrm{HPO}_{4}$ and $\mathrm{KH}_{2} \mathrm{PO}_{4}$ and adjusting the $\mathrm{pH}$ with $\mathrm{NaOH}$. The common chemicals used for preparation of buffers were of analytical reagent grade. All of the solutions were prepared with deionized distilled (D-D) water.

\subsection{Enzymes immobilization}

A commercial glucose test strip (Boehringer-Mannheim) consisting of two palladium strip electrodes was used. The palladium strips at the enzyme loaded pad of the commercial glucose test strip were modified and connected to a laboratory-built potentiostat. The nude palladium electrodes were served as the working and counter electrodes, as shown in Fig. 1. The working area of the working electrode was $4.8 \mathrm{~mm}^{2}$. The enzymes were immobilized on the electrode by a combination of PVA-SbQ photo-crosslinking and glutaraldehyde exposure. An enzyme solution with an activity of $70 \mathrm{U} \mathrm{ml}^{-1}$ was prepared by mixing $50 \mathrm{mg}$ PVA-SbQ, $10 \mathrm{mg}$ BSA and $140 \mathrm{mg}$ of L-GLOx with an activity of $70 \mathrm{U} \mathrm{ml}^{-1}$. A $1 \mu \mathrm{l}$ of the solution was applied onto the active area of the electrode, which was then placed in a dark sealed box and a plastic cup containing $0.5 \mathrm{ml}$ glutaraldehyde on the bottom of the box. After the glutaraldehyde evaporated at room temperature for $30 \mathrm{~min}$, the box was maintained at $4{ }^{\circ} \mathrm{C}$ for $8 \mathrm{~h}$ to allow the formation of enzyme-to-enzyme and enzyme-toBSA covalent linkages. The sensor was then exposed to UV light for $25 \mathrm{~min}$. The cross-linking of the polymer PVA-SbQ occurs (Fig. 2A) when UV radiation induces cyclodimerization of the styrylpyridinium groups which produces a porous network-like matrix to entrap enzymes.

\subsection{Apparatus and measurement procedure}

Amperometric measurements were performed using a laboratory-built potentiostat. The noise level of the detection system was within $1 \mathrm{nA}$. Input and output signals from the potentiostat were coupled to a PC (Pentium $433 \mathrm{MHz}$ ) using a peripheral interface card (AT-MIO-16E, National Instruments, Austin, TX, USA). The interface card consisted of a 16-channel analog-todigital (A/D) converter (12 bit) and a 2-channel digital-to-analog (D/A) converter (12 bit). Voltage output, data display and recording were programmed using the LabVIEW 6.1 software package (National Instruments, Austin, TX, USA). All measurements were made using a three-electrode system which employed an $\mathrm{Ag} / \mathrm{AgCl}$ electrode as a reference and a modified commercially palladium strip $\left(4.8 \mathrm{~mm}^{2}\right)$ as the working and counter electrodes. The amperometric measurements were performed at $400 \mathrm{mV}$ versus the $\mathrm{Ag} / \mathrm{AgCl}$ reference electrode. The working solution was $9.9 \mathrm{ml}$ PBS buffer (pH 7.0) in a cylindrical cell, with temperature controlled using a thermostat. All experiments were carried out at $35^{\circ} \mathrm{C}$. For the amperometric measurement of MSG by the steady-state method, $0.1 \mathrm{ml}$ of MSG solution was injected into the test solution using a microsyringe after a steady state of the testing-system had been obtained. The baseline current was measured, and then, following the injection of MSG, the response current was displayed and simultaneously logged by the computer until a steady state was achieved. Magnetic stirring during the operation was used to ensure the homogeneity of the solution. The difference between the baseline and the steady-state current was used to calculate the concentration of MSG. For the amperometric measurement of MSG by the kinetic method, the current-time curves were recorded at a potential of $0.4 \mathrm{~V}$ versus the $\mathrm{Ag} / \mathrm{AgCl}$ reference electrode. After decreasing the current to its low initial or background level, solution doses of known MSG concentration were added to the reagent cell. The current-time curve was recorded. The initial rate of current increase, which was recorded $10 \mathrm{~s}$ after the sample was added, was used to calculate the concentration of MSG. 


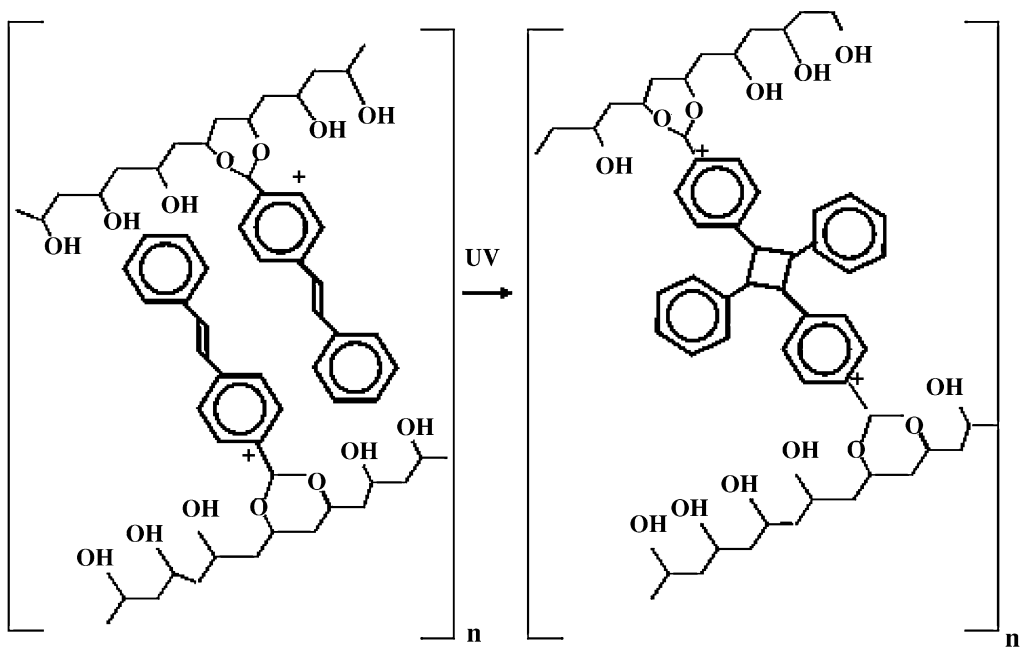

(A)

Photocrosslinking of the PVA-SbQ membrane

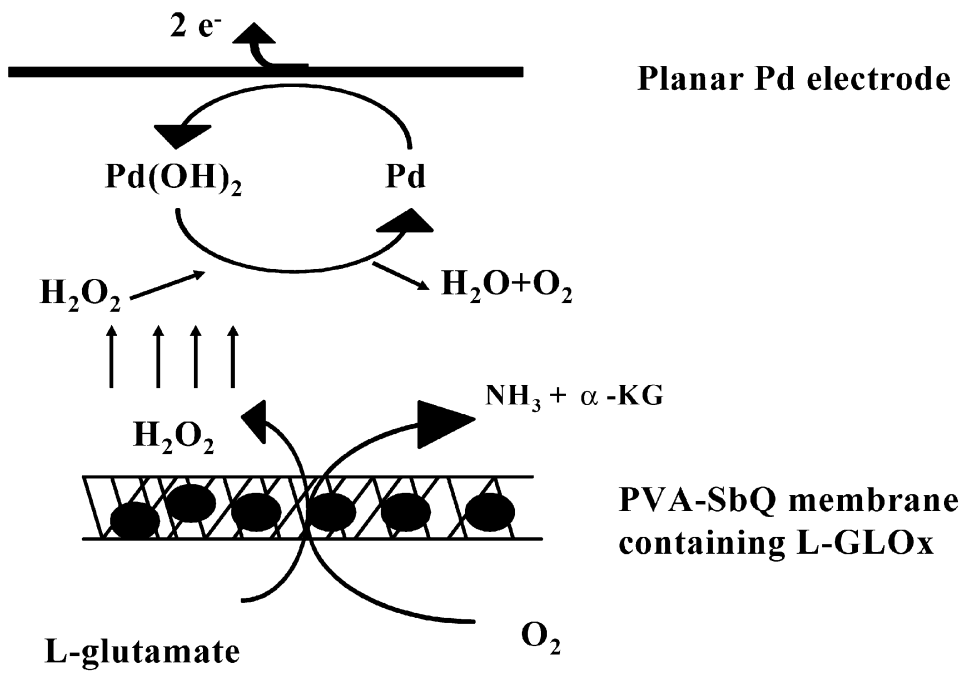

(B) Reactions involved in the MSG concentration determination

Fig. 2. (A) Photo-crosslinkable of the PVA-SbQ membrane. (B) Schematic of the enzyme and the electrode reactions involved in determining the L-glutamate concentration at the surface of a Pd/PVA-SbQ-L-GLOx electrode.

The long-term stability of the electrodes was assessed by measuring $100 \mu \mathrm{M}$ MSG every month over a 180-day period. Prior to electrochemical analysis, the electrodes were pre-wetted by immersion in the phosphate buffer solution $(\mathrm{pH}$ 7.0) for $30 \mathrm{~min}$. Each data point is the mean value of three measurements by three individual electrodes.

\section{Results and discussion}

\subsection{Effect of PVA-SbQ content on the sensor response}

The biocatalyst scheme used to measure L-glutamate concentration is illustrated in Fig. 2B. The L-glutamate can be converted to $\mathrm{H}_{2} \mathrm{O}_{2}, \alpha-\mathrm{KG}$ and $\mathrm{NH}_{3}$ by L-GLOx. $\mathrm{H}_{2} \mathrm{O}_{2}$ is an electroactive species, which can easily be oxidized leading to an increase in current. PVA-SbQ is a polyvinyl alcohol with a styrylpyridinium residue as its photosensitive groups. The cross-linking of the polymer is induced using UV radiation to generate cyclodimerization of the styrylpyridinium groups (Fig. 2A). As shown in Fig. 3A (left), only 50\% of the original response of the L-glutamate sensor was restored after $4 \mathrm{~h}$ of immersion in the phosphate buffer. The loss of response (Fig. 3B, left) was attributed to the escape of the enzyme from numerous pores of the PVA-SbQ matrix which formed in the dissolved area of the membrane [13]. In order to avoid a decreased response due to the escape of the L-GLOx (molecular weight of $1.6 \times 10^{5} \mathrm{Da}$ [29]) from the PVA-SbQ matrix, we combined PVA-SbQ with glutaraldehyde to fabricate the enzyme membrane. The reaction of glutaraldehyde with a primary amino group by the formation of Schiff-base bonds has been used in applications involving covalently binding compounds and protein-containing amino groups. In our sensor, the reaction of L-GLOx with the bifunctional reagent glutaraldehyde was used to create an enzyme/glutaraldehyde/enzyme cross-link in 

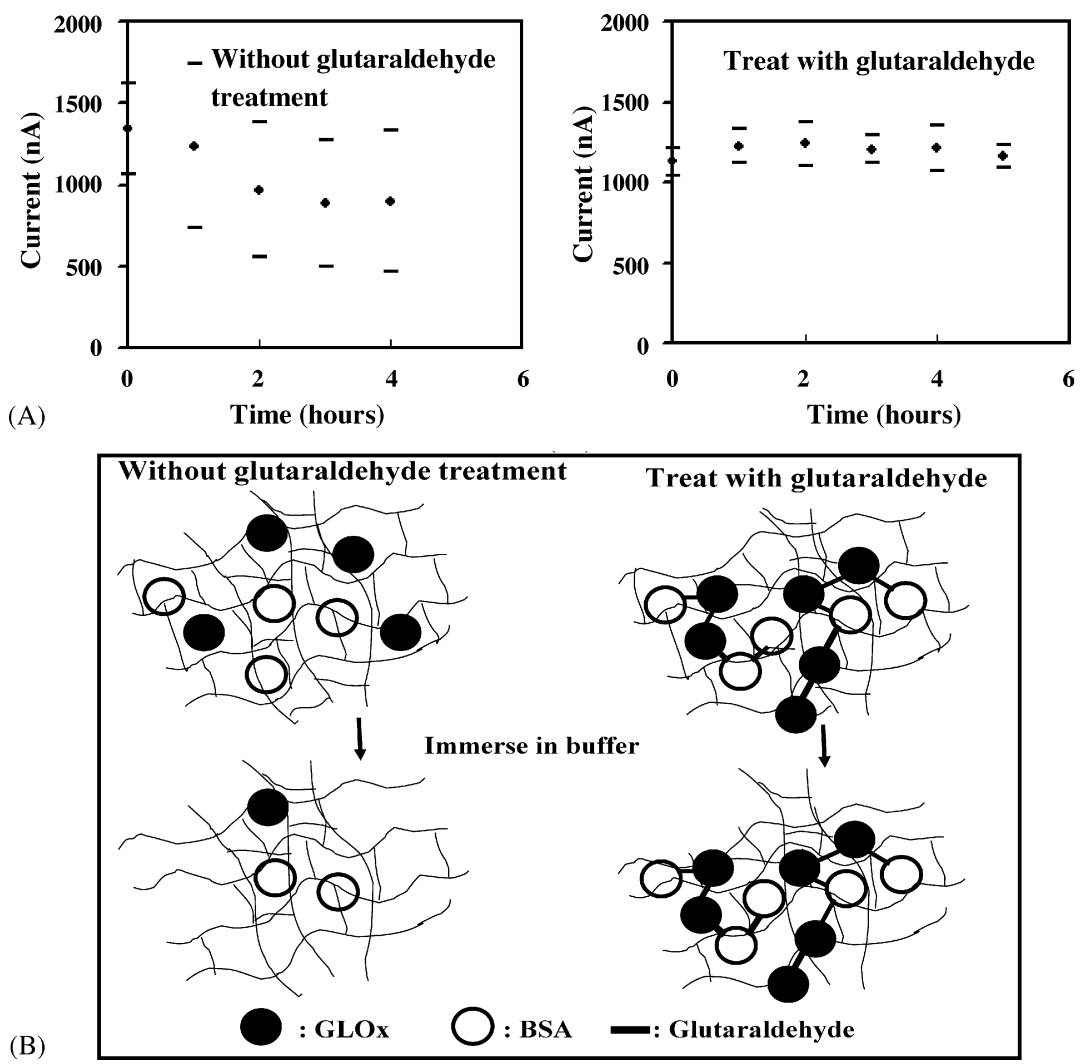

Fig. 3. (A) Stability of the enzyme electrode with and without glutaraldehyde exposure. (B) Schematic of the immobilization of the enzyme with and without glutaraldehyde exposure. The electrodes were immersed in the phosphate buffer when not in use. Measurements were carried out with $100 \mu \mathrm{M}$ MSG as a substrate in a $100 \mathrm{mM}$ sodium phosphate buffer $(\mathrm{pH} 7.0)$ at $35^{\circ} \mathrm{C}$. The polarizing potential applied to the sensor was $400 \mathrm{mV}$ vs. the $\mathrm{Ag} / \mathrm{AgCl}$ reference electrode. Each data point is the mean value of five measurements.

order to prevent the enzyme from escaping from the PVA-SbQ matrix (Fig. 3B, right). The response for the enzyme electrode in $100 \mu \mathrm{M}$ MSG increased slightly during the initial $4 \mathrm{~h}$.

\subsection{Optimal enzyme immobilization conditions}

The optimal glutaraldehyde treatment process for constructing an L-glutamate amperometric sensor was studied. Previous study demonstrated glutaraldehyde to be an effective cross-link agent for glucose oxidase [30], but also one which reduced the activity of invertase [14]. These results suggest that glutaraldehyde may cause the denaturing of invertase. In this study, we found that the response of the sensor was ca. 100-fold weakened if the enzyme solution was directly mixed with a $1 \%(\mathrm{v} / \mathrm{v})$ aqueous solution of glutaraldehyde for $30 \mathrm{~min}$. However, when the enzyme solution was exposed to glutaraldehyde saturated vapor, the response of the L-GLOx electrodes did not change significantly even after exposure for $12 \mathrm{~h}$. These findings indicate that the L-GLOx electrode can resist exposure to glutaraldehyde vapor for at least $12 \mathrm{~h}$. An exposure time of $12 \mathrm{~h}$ was thus chosen for the following tests to achieve complete enzyme-toenzyme and enzyme-to-BSA cross-linkage. The effect of the BSA concentration on the sensitivity and reproducibility of the L-glutamate biosensor was also examined (Table 1). It was hypothesized that BSA may react with the plus-charged SbQ group, reducing the coulombic interaction $[13,31]$ between the enzyme and the SbQ group. This could explain the biosensor response increases when 2.5\% BSA was mixed with PVA-SbQ solution. The response was weaker when the BSA concentration exceeded $2.5 \%$ because the diffusion-limiting membrane associated with the exclusion of the substrate from the interior of the gel led to a strengthening effect in the influence of mass transport. Furthermore, the reproducibility was poor at high BSA concentration because the enzyme solution was unevenly distributed on the surface of the planar electrode. The addition of a surface active agent $(0.01 \%$ Fluorad FC-430) to the enzyme

Table 1

Effect of BSA concentration on the response and reproducibility among electrodes of the L-glutamate sensor $(n=3)$

\begin{tabular}{llc}
\hline BSA $^{\mathrm{a}}(\%)$ & Response $^{\mathrm{b}}(\mathrm{nA})$ & R.S.D. $(\%)$ \\
\hline 0 & 1386 & 6.05 \\
1.5 & 1450 & 5.32 \\
2.5 & 1780 & 9.04 \\
5.0 & 1299 & 16.64 \\
$5.0^{\mathrm{c}}$ & 998 & 7.43 \\
10 & 673 & 19.64 \\
20 & 342 & 7.43 \\
\hline
\end{tabular}

a Containing 25\% PVA-SbQ.

b Measurements were carried out with $100 \mu \mathrm{M}$ L-glutamate as a substrate in a $100 \mathrm{mM}$ sodium phosphate buffer ( $\mathrm{pH} 7.0)$ at $35^{\circ} \mathrm{C}$. The polarizing potential applied to the sensor was $400 \mathrm{mV}$ vs. the $\mathrm{Ag} / \mathrm{AgCl}$ reference electrode.

c $0.01 \%$ Fluorad FC-430 was added as surface active agent. 


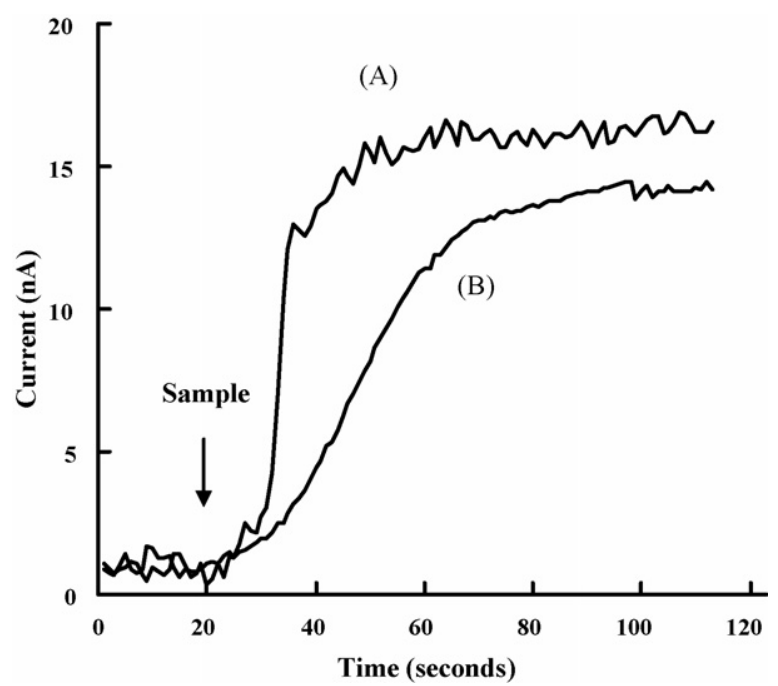

Fig. 4. Current-time plots of the enzyme electrode: (A) electrode immersed in a phosphate buffer for $24 \mathrm{~h}$ and (B) freshly fabricated electrode. Measurements were carried out with $10 \mu \mathrm{M}$ MSG as a substrate in a $100 \mathrm{mM}$ sodium phosphate buffer $\left(\mathrm{pH} \mathrm{7.0)}\right.$ at $35^{\circ} \mathrm{C}$. The polarizing potential applied to the sensor was $400 \mathrm{mV}$ vs. the $\mathrm{Ag} / \mathrm{AgCl}$ reference electrode.

solution improved the reproducibility. This was attributed to the more even distribution of solution on the surface of the planar electrode. However, the long-term stability of the proposed planar electrode declined when the surface active agent was added (data not shown). The determination of more effective alternatives to improve the reproducibility from electrode to electrode including pre-anodization [32], electrochemical cycling [33] and plasma treatment [34] of the electrode will require further study.

Finally, the electrode was dipped in $0.5 \%(\mathrm{w} / \mathrm{v})$ cellulose triacetate in dichloromethane for $3 \mathrm{~s}$ and dried for $5 \mathrm{~min}$ at room temperature. Cellulose triacetate has been used as a diffusionlimiting membrane for needle-type glucose sensors [30]. In this study, the PVA-SbQ membrane was found to dissolve completely in dichloromethane. Accordingly, cellulose triacetate was considered inappropriate for use as the diffusion-limiting membrane for the planar electrode. Therefore, PVA-SbQ membrane without cellulose triacetate was selected for use as the diffusion-limiting membrane in the fabrication of the planar glucose sensor.

Fig. 4 shows a plot of current against time for the enzyme electrode. The response of the electrode immersed in the phosphate buffer for $24 \mathrm{~h}$ (Fig. 4 line A) was seven-fold faster than that of the freshly fabricated electrode (Fig. 3 line B). Figs. 2 and 3 illustrate that after immersion in the buffer, the enzyme electrode responded sensitively and rapidly. Fig. 4, line A, shows a typical response of the sensor to $10 \mu \mathrm{M}$ MSG. The current sharply increased initially and quickly to achieve a maximum. The current of the sensor started to increase approximately $3 \mathrm{~s}$ after the injection of MSG, reaching a $95 \%$ steady-state current within $20 \mathrm{~s}$. These findings may be explained as follows: (1) the membrane swelled after immersion of the electrode in the phosphate buffer for $24 \mathrm{~h}$ similarly to previously reported results [21].

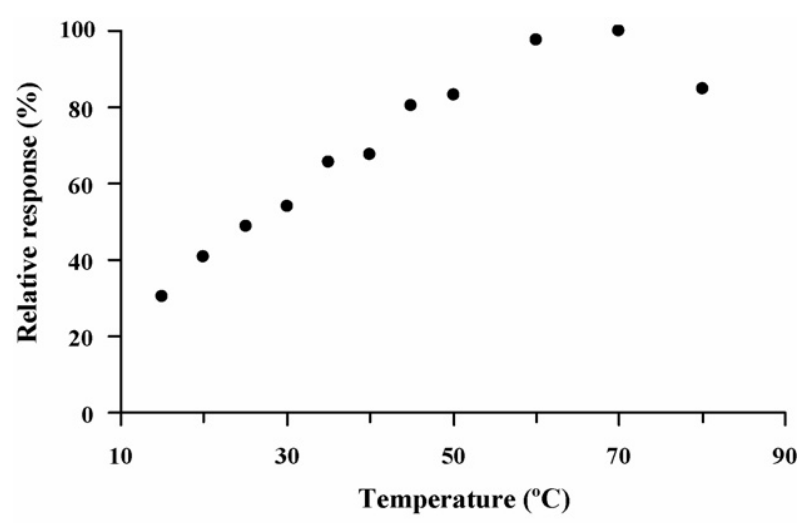

Fig. 5. Effect of the operative temperature on the response of the L-glutamate sensor. Measurements were carried out with $100 \mu \mathrm{M}$ MSG as a substrate in a $100 \mathrm{mM}$ sodium phosphate buffer ( $\mathrm{pH}$ 7.0). The polarizing potential applied to the sensor was $400 \mathrm{mV}$ vs. the $\mathrm{Ag} / \mathrm{AgCl}$ reference electrode.

(2) $1.10 \%$ mol SbQ was used to immobilize the enzyme in this experiment. A previous study [31] found that $10 \%$ of the polymer membrane was soluble when the SbQ content was $1.10 \%$. The soluble polymer leached out of the polymer matrix when the electrode was immersed in the buffer, resulting in the formation of a more porous polymer matrix. Oxygen and/or substrate can be rapidly transported into the hydrogel matrix, increasing the reaction rate.

\subsection{Effect of PVA-SbQ on the optimal operation $p H$ and temperature of the sensor}

The influence of temperature on the sensitivity of the enzyme electrode was also studied in the range from 15 to $80^{\circ} \mathrm{C}$ (Fig. 5). The maximum sensitivity was observed at $65^{\circ} \mathrm{C}$. This temperature is $15^{\circ} \mathrm{C}$ above the maximum sensitivity temperature observed for soluble L-GLOx [35], indicating that the PVASbQ immobilization improved the stability of the enzyme. The decrease in response when the temperature exceeded $65^{\circ} \mathrm{C}$ was thought to be due to thermal degradation of the L-GLOx. Although the responsiveness of the electrode was enhanced at higher temperatures, the response of the sensor became unstable when the temperature reached $50{ }^{\circ} \mathrm{C}$ (data not shown). A temperature of $35^{\circ} \mathrm{C}$ was thus chosen for the following tests after consideration of both the normal body temperature and the stability profile of the electrode. The effect of $\mathrm{pH}$ on the response of the electrode was examined in the $\mathrm{pH}$ range from 5.0 to $9.5 \mathrm{using}$ amperometry in stirred solution at $400 \mathrm{mV}$ versus the $\mathrm{Ag} / \mathrm{AgCl}$ reference electrode (data not shown). The maximum sensitivity was observed for buffer solutions adjusted to $\mathrm{pH}$ 7.0. This $\mathrm{pH}$ was close to the optimal value observed for the catalytic behavior of soluble L-GLOx, revealing that the PVA-SbQ membrane did not change this property [35]. Positively charged PVA-SbQ matrices are known to change the optimal $\mathrm{pH}$ value for the immobilized enzymes [13]. However, the polymer used in the present work had negligible influence on the optimal $\mathrm{pH}$ value of $\mathrm{L}$ glutamate oxidase. Consequently, this medium was selected for use in all subsequent experiments. 


\subsection{Current-time and calibration curves of the $\mathrm{L}$-glutamate sensor for the measurement of MSG concentration}

The amperometric current was recorded continuously at $400 \mathrm{mV}$ working electrode potential. After obtaining a steady background current, a given volume of the MSG sample solution was injected into the test solution using a microsyringe. Magnetic stirring during the operation was used to ensure the homogeneity of the solution. Soon after the injection, the amperometric current started to increase, indicating hydrogen peroxide production. Fig. 6A, line 1, presents a typical response of a freshly fabricated electrode to $100 \mu \mathrm{M}$ MSG. The response time seems to be more than $10 \mathrm{~s}$ and the $95 \%$ of the steady-state signal is reached after approximately $50 \mathrm{~s}$. The electrode responded more slowly than that after immersed in the phosphate buffer for $24 \mathrm{~h}$, as described above (Fig. 4, line A). The calibration curves of a biosensor were conventionally obtained according to two basic methods; the steady-state method and the kinetic method. Comparison of reproducibility of the results obtained using the steady-state method and the kinetic method for the L-glutamate sensor are shown in Table 2. The experiment was performed immediately after the electrode was fabricated. Table 2 shows
Table 2

Comparison of reproducibility of results for the L-glutamate sensor obtained using the steady-state and the kinetic method $(n=7)$

\begin{tabular}{lcl}
\hline Method & S.D. & Mean (R.S.D. \%) \\
\hline Steady-state method ${ }^{\mathrm{a}}(\mathrm{nA})$ & 40.7 & $1101(3.69)$ \\
Kinetic method $^{\mathrm{a}}\left(\mathrm{nA} \mathrm{s}^{-1}\right)$ & 2.08 & $27.07(7.70)$ \\
\hline
\end{tabular}

${ }^{\text {a }}$ Measurements were carried out with $100 \mu \mathrm{M}$ MSG as a substrate in a $100 \mathrm{mM}$ sodium phosphate buffer $(\mathrm{pH} 7.0)$ at $35^{\circ} \mathrm{C}$. The polarizing potential applied to the sensor was $400 \mathrm{mV}$ vs. the $\mathrm{Ag} / \mathrm{AgCl}$ reference electrode.

the very low relative standard deviation (3.69\%) obtained for a steady-state sensor response. The curves obtained with the kinetic method were less reproducible, and corresponded to a very high relative standard deviation (7.70\%). The results revealed that the steady-state method had greater reproducibility than the kinetic method for determining MSG concentration. The poor reproducibility of the kinetic method was attributed to the irregular shapes of the current-time curves in the first few tests of the electrode (Fig. 6A, line 2). The response shifted occasionally before the current reached stability as the reaction time increased. These findings may be attributable to two factors.
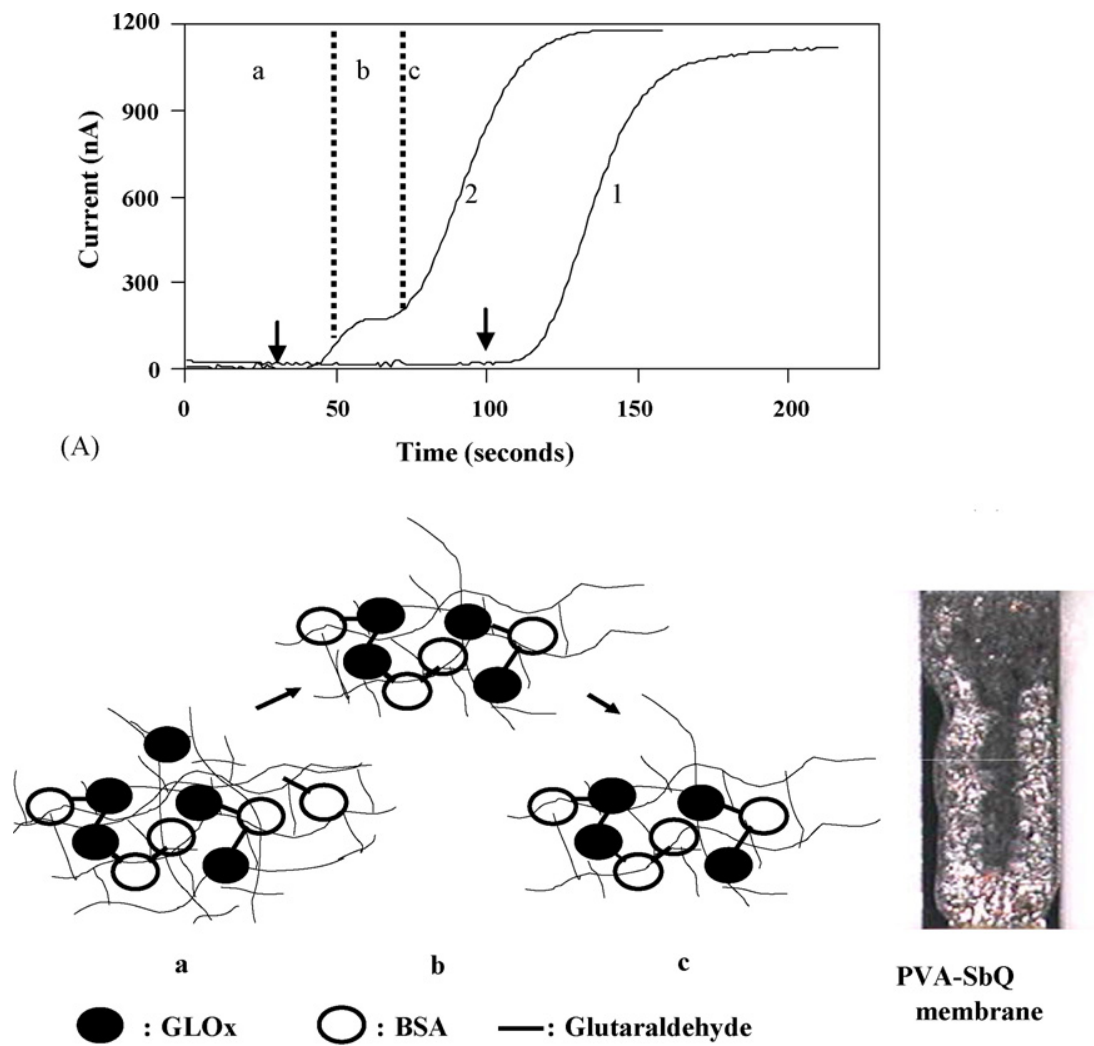

(B)

(C)

Fig. 6. (A) Current-time plots of the enzyme electrode. Line 1 represents a typical response curve of the biosensor. Line 2 represents the irregularly shaped current-time curves of the biosensor. The response was occasionally shifted when several seconds of gate time had elapsed before the current began to reach a stable state as the reaction continued. Measurements were carried out with $100 \mu \mathrm{M} \mathrm{MSG}$ as a substrate in a $100 \mathrm{mM}$ sodium phosphate buffer (pH 7.0) at $35^{\circ} \mathrm{C}$. The arrows indicate the time points of substrate addition. (B) Schematic of the proposed enzyme leakage. (a) Enzyme entrapment in the PVA-SbQ matrix; (b) leakage of some of the enzyme due to the dissolution of the PVA-SbQ polymer and the flaking off the polymer matrix; (c) the electrode reaches a stable state. (C) Uneven distribution of PVA-SbQ membrane on the planar electrode. 


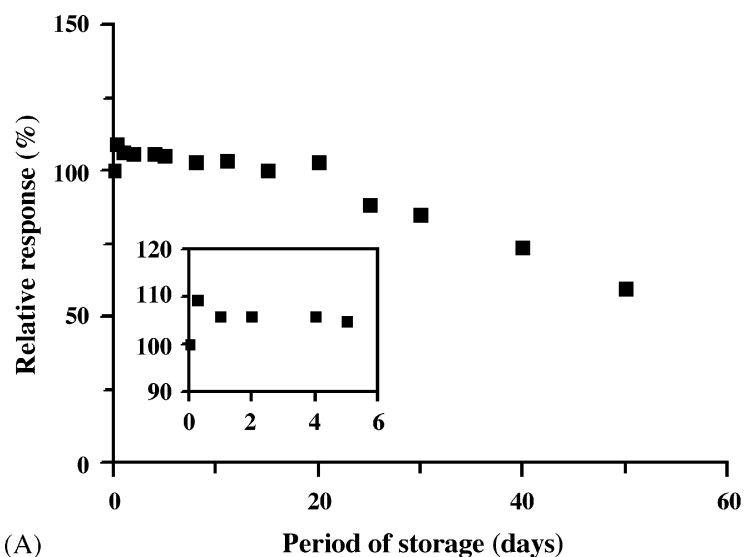

(A)

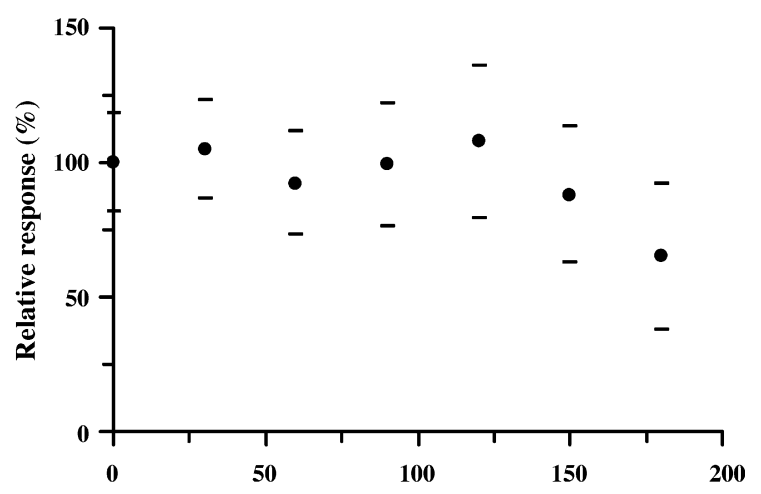

(B)

Period of storage (days)

Fig. 7. Stability of the L-glutamate sensor during storage in (A) a phosphate buffer and (B) a dark dry state. Measurements were carried out with $100 \mu \mathrm{M}$ MSG as a substrate in a $100 \mathrm{mM}$ sodium phosphate buffer $(\mathrm{pH} 7.0)$ at $35^{\circ} \mathrm{C}$. Each data point is the mean value of three measurements by three individual electrodes. The polarizing potential applied to the sensor was $400 \mathrm{mV}$ vs. the $\mathrm{Ag} / \mathrm{AgCl}$ reference electrode.

(1) The polymer dissolved and flaked off the polymer matrix (Fig. 6B) resulting in a weakened response. (2) The PVA-SbQ polymer was unevenly distributed on the surface of the planar electrode (Fig. 6C).

When the steady-state sensor response method was used, the enzyme electrode exhibited a linear calibration range at of MSG concentrations from $50 \mathrm{nM}$ to $100 \mu \mathrm{M}$, with a slope of $12.18 \mathrm{nA} / \mu \mathrm{M}$ and a correlation coefficient of $0.997(n=10)$. When an MSG concentration of $10 \mu \mathrm{M}$ was used for successive tests, and the response of the electrode was continuously measured every $2 \mathrm{~min}$ over a $200 \mathrm{~min}$ period, no significant difference was found in the response to $10 \mu \mathrm{M}$ MSG over a total of 100 tests. The relative standard deviation (R.S.D.) was $2.6 \%$.

\subsection{Long-term stability and reproducibility of the $\mathrm{L}-$ glutamate sensor in the measurement of MSG concentration}

The storage conditions affected the stability of the sensor. Fig. 7A shows that when the electrodes were stored in the phosphate buffer ( $\mathrm{pH} 7.0)$ solution at $4{ }^{\circ} \mathrm{C}$, an initial, sharp increase in the activity of the enzyme electrode was followed by an almost identical response for up to 20 days after which there was a gradual decrease in response up to about 50 days. Fig. 7A also shows that the proposed electrode retained $80 \%$ of its initial response activity up to 30 days. This result is in agreement with previous findings regarding the stability of butyrylcholinesterase and L-lactase electrodes [12,19] in similar experiments. Fig. 7A (inset) also shows that the proposed electrode reached a stable state within $24 \mathrm{~h}$. The stability of the proposed planar electrode was better than those of most commercial membrane covered electrodes, which have a shelf-life of about 10 days, but was inferior to that of conventional three-dimensional electrodes [11]. The stability of our fabricated sensor when stored in the phosphate buffer was attributed to the method of combining photo-crosslinking of PVA-SbQ with a bifunctional agent (such as glutaraldehyde) to immobilize the enzyme, preventing its leakage. The reduced activity of the enzymatic electrode was considered to result from the dissolution of the enzymatic membrane during storage, since the PVA-SbQ film dissolves when the SbQ content is low [34].

When the sensors were stored under dry conditions, the response did not change during the storage period of 150 days (Fig. 7B). Most of the functional characteristics were restored within 5 min (wet-up time) of repeated wetting and drying and were maintained for several months thereafter. These findings suggest that numerous $\mathrm{OH}$ groups are present in the PVA-SbQ matrix, the enzymes are maintained in a hydrophilic environment even when dry, and a favorable hydrophilic environment around the enzyme is required to avoid its denaturing $[12,36]$ and to restore its functional characteristics. When the sensors were stored under dry conditions, the stability of the proposed planar electrode was comparable to those of conventional threedimensional electrodes, which have a shelf-life of about 300 days [11]. The between-electrode reproducibility of the sensor was also examined. Notably, the biosensors obtained from eight individual electrodes showed poor reproducibility with R.S.D.s of $12.75 \%$, because the enzyme membrane was unevenly distributed on the electrode surface, as shown in Fig. 6C. More effective alternatives which might be adopted to improve the between-electrode reproducibility include pre-anodization [32], electrochemical cycling [33] and plasma treatment [34], but will require further study.

\subsection{Comparison of proposed planar amperometric biosensor with other methods for MSG concentration measurement}

The proposed planar amperometric L-glutamate biosensor obtained a lower detection limit $(0.05 \mu \mathrm{M})$ for MSG determination in comparison with other methods for MSG concentration measurement (Table 3). The long-term stability of the proposed planar amperometric L-glutamate biosensor was also superior to other systems for the measurement of L-glutamate, which have a shelf-life of less than 80 days and was also better than most commercial membrane covered electrodes which have a shelf-life of about 10 days [22-28]. Thus, development of a real time and complete automation procedure is possible in combination with a sample collector and flow injection system. 
Table 3

The range and stability of various L-glutamate measurement systems

\begin{tabular}{|c|c|c|c|c|c|}
\hline Method & Enzyme & Measurement range & Stability (day) & R.S.D. $(\%)$ & Reference \\
\hline Potentiometric & L-Glutamate decarboxylase & $2.5-75 \mathrm{mM}$ & 78 & 5 & {$[22]$} \\
\hline Fluorimeteric & L-Glutamate dehydrogenase & $2.5-50 \mu \mathrm{M}$ & 70 & $4.3-7.3$ & {$[23]$} \\
\hline Fluorimeteric & L-Glutamate oxidase; catalase & $10-500 \mu \mathrm{M}$ & - & $<2$ & {$[24]$} \\
\hline Amperometric & L-Glutamate oxidase & $2-20 \mathrm{mM}$ & $>30$ & 0.4 & [26] \\
\hline Amperometric (integrated) & L-Glutamate oxidase & $0.5-60 \mu \mathrm{M}$ & - & - & [27] \\
\hline Amperometric & L-Glutamate oxidase & $10-300 \mu \mathrm{M}$ & - & 1.7 & [28] \\
\hline
\end{tabular}

(-) Not shown.

\section{Conclusions}

The stability of the proposed planar L-glutamate amperometric biosensor is better than most commercial membrane covered biosensors, which have a shelf-life of about 10 days. When the proposed sensor was stored under dry conditions, a time less than 10 min of repeated wetting and drying was required to restore most of its functional characteristics after a period of storage of several months. The stability of the planar biosensor when immersed in a phosphate buffer can be improved by optimizing the SbQ content of the vinyl polymer backbone or by using a more effective electrode conformation to anchor the membrane. Compared with other methods for MSG concentration measurement, the planar L-glutamate amperometric biosensor achieved a lower detection limit $(0.05 \mu \mathrm{M})$ and longer shelf-life. Such a planar electrode is thus suitable for further development for use in analyzing food samples.

\section{Acknowledgement}

The authors would like to thank the National Science Council of the Republic of China for financially supporting this research under Contract No. NSC-92-2113-M-002-053.

\section{References}

[1] E. Bakker, Electrochemical sensors, Anal. Chem. 76 (2004) 3285-3298.

[2] D.R. Thévenot, K. Toth, R.A. Durst, G.S. Wilson, Electrochemical biosensors: recommended definitions and classification, Biosens. Bioelectron. 9 (2001) 121-131.

[3] B. Palenzuela, B.M. Simonet, R.M. Garćýa, A. Ŕýos, M. Valcárcel, Amperometric screening of bacterial food contamination using a composite modified electrode, Anal. Chim. Acta 524 (2004) 167-174.

[4] J. Castillo, S. Gáspár, S. Leth, M. Niculescu, A. Mortari, I. Bontidean, V. Soukharev, S.A. Dorneanu, A.D. Ryabov, E. Csöregi, Biosensors for life quality design, development and applications, Sens. Actuators B 102 (2004) 179-194.

[5] J. Zeravik, P. Skladal, Screen-printed amperometric immunosensor for repeated use in the flow-through mode, Electroanalysis 11 (1999) 851-856.

[6] G. Cui, J.H. Yoo, B.W. Woo, S.S. Kim, G.S. Cha, H. Nam, Disposable amperometric glucose sensor electrode with enzyme-immobilized nitrocellulose strip, Talanta 54 (2001) 1105-1111.

[7] K. Grennan, A.J. Killard, M.R. Smyth, Physical characterizations of a screen-printed electrode for use in an amperometric biosensor system, Electroanalysis 13 (2001) 745-750.

[8] M. Albareda-Sirvent, A. Merkoci, S. Alegret, Configurations used in the design of screen-printed enzymatic biosensors. A review, Sens. Actuators B 69 (2000) 153-163.
[9] H. Ludi, Planar electrochemical biosensors for critical-care applications. IVD Technology, 1999, http://www.devicelink.com/ivdt/archive/99/09/ 009.html.

[10] R. Singhal, W. Takashima, K. Kaneto, S.B. Samanta, S. Annapoorni, B.D. Malhotra, Langmuir-Blodgett films of poly-3-dodecyl thiophene for application to glucose biosensor, Sens. Actuators B 86 (2002) 42-48.

[11] B.D. Malhotra, A. Chaubey, Biosensors for clinical diagnostics industry, Sens. Actuators B 91 (2003) 117-127.

[12] N. Jaffrezic-Renault, A. Senillou, C. Martelet, K. Wan, J.M. Chovelon, ISFET microsensors for the detection of pollutants in liquid media, Sens. Actuators B 59 (1999) 154-164.

[13] K. Ichimura, S. Watanabe, Immobilization of enzymes with use of photosensitive polymers having the stabazolium group, J. Polym. Sci., Polym. Chem. Ed. 18 (1980) 891-902.

[14] K. Ichimura, A convenient photochemical method to immobilize enzyme, J. Polym. Sci., Polym. Chem. Ed. 22 (1984) 2817-2828.

[15] J.D. Newman, S.F. White, I.E. Tothill, A.P.F. Turner, Catalytic materials, membranes and fabrication technologies suitable for the construction of amperometric biosensors, Anal. Chem. 67 (1995) 4594-4599.

[16] J.L. Marty, N. Mionetto, R. Rouillon, Entraped enzymed in photocrosslinkable gel for enzyme electrode, Anal. Lett. 25 (1992) 1389-1398.

[17] B.K. Sohn, B.W. Cho, C.S. Kim, D.H. Kwon, ISFET glucose and sucrose sensors by using platinum electrode and photo-crosslinkable polymers, Sens. Actuators B 41 (1997) 7-11.

[18] I. Perdomo, C. Sundermeier, H. Hinkers, O.M. Morell, W. Seirt, M. Knoll, Containment sensors for the determination of L-lactate and glucose, Biosens. Bioelectron. 14 (1999) 27-32.

[19] I. Perdomo, H. Hinker, H. Sundermeier, W. Seifert, O. Martinez, M. Knoll, Miniaturized real-time monitoring system for L-lactate and glucose using microfabricated multi-enzyme sensors, Biosens. Bioelectron. 14 (2000) 515-522.

[20] S. Andreescu, L. Bar, J.L. Marty, Immobilization of acetylcholinesterase on screen-printed electrodes: comparative study between three immobilization methods and applications to the detection of organophosphorus insecticides, Sens. Actuators B 64 (2002) 171-180.

[21] B. Wang, B. Li, Q. Deng, S. Dong, Amperometric glucose biosens or based on sol-gel organic-inorganic hybrid material, Anal. Chem. 70 (1998) 3170-3174.

[22] M.I.P. Oliveira, M.C. Pimentel, M.C.B.S.M. Montenegro, A.N. Araújo, M.F. Pimentel, V.L. da Silva, L-Glutamate determination in food samples by flow-injection analysis, Anal. Chim. Acta 448 (2001) 207-213.

[23] W. Khampha, J. Yakovleva, D. Isarangkul, S. Wiyakrutta, V. Meevootisom, J. Emnéus, Specific detection of L-glutamate in food using flow-injection analysis and enzymatic recycling of substrate, Anal. Chim. Acta 518 (2004) 127-135.

[24] T. Tsukatani, K. Matsumoto, Sequential fluorometric quantification of $\gamma$ aminobutyrate and L-glutamate using a single line flow-injection system with immobilized-enzyme reactors, Anal. Chim. Acta 546 (2005) 154160.

[25] W. Khampha, V. Meevootisom, S. Wiyakrutta, Spectrophotometric enzymatic cycling method using L-glutamate dehydrogenase and Dphenylglycine aminotransferase for determination of L-glutamate in foods, Anal. Chim. Acta 520 (2004) 133-139. 
[26] B.C. Ye, Q.S. Li, Y.R. Li, X.B. Li, J.T. Yu, L-Glutamate biosensor using a novel $\mathrm{L}$-glutamate oxidase and its amplification to flow injection analysis system, J. Biotechnol. 42 (1995) 45-52.

[27] J. Castillo, A. Blöchl, S. Dennison, W. Schuhmann, E. Csöregi, Glutamate detection from nerve cells using a planar electrodes array integrated in a microtiter plate, Biosens. Bioelectron. 20 (2005) 2116-2119.

[28] K. Matsumoto, K. Sakoda, Y. Osajima, Determination of L-glutamate by ampero, etric flow-injection analysis using immobilized glutamate oxidase: manifold for simultaneous detection of component signal and blank signal, Anal. Chim. Acta 261 (1992) 155-159.

[29] W.T. Wu, Gene cloning characterization secretion mechanism and enzyme kinetics of L-glutamate oxidase, Doctoral Thesis, Graduate Institute of Agriculture Chemistry, National Taiwan University, 1999, p. 45.

[30] C.Y. Chen, Y.C. Su, K. Isbibara, N. Nakabayashi, E. Tamiya, I. Karube, Biocompatible needly-type glucose sensor with potential for use in vivo, Electroanalysis 5 (1993) 269-276.

[31] R. Rouillon, M. Tocabens, J.L. Marty, Stabilization of chloroplasts by entrapment in polyvinylalcohol bearing styrylpyridinium groups, Anal Lett. 27 (1994) 2239-2248.

[32] G. Cui, J.H. Yoo, J.S. Lee, J. Yoo, J.H. Uhm, G.S. Cha, H. Nam, Effect of pre-treatment on the surface and electrochemical properties of screenprinted carbon paste electrodes, Analyst 126 (2001) 1399-1403.

[33] W.B. Nowall, W.G. Kuhr, Electrocatalytic surface for the oxidation of NADH and other anionic molecules of biological significance, Anal. Chem. 67 (1995) 3583-3588.

[34] E.J. Kim, T. Haruyama, Y. Yanagida, E. Kobatake, M. Aizawa, Disposable creatinine sensor based on thick-film hydrogen peroxide electrode system, Anal. Chim. Acta 394 (1999) 225-231.

[35] C.Y. Chen, Studies on the purification and application of biosensor using oxidase as biomaterials. Doctoral Thesis, Graduate Institute of Agriculture Chemistry, National Taiwan University, 1987, p. 226.
[36] K. Wan, J.M. Chovelon, N. Jaffrezic-Renault, A.P. Soldatkin, Sensitive detection of pesticide using ENFET with enzymes immobilized by crosslinking and entrapment method, Sens. Actuators B 58 (1999) 399-408.

\section{Biographies}

Ku-Shang Chang received his PhD degree in microbiological and biological engineering from the Taiwan University, Taipei, Taiwan. He is currently an associate professor in the Department of Food Science at Yuanpei University of Science \& Technology, Hsinchu, Taiwan. His research interests include food science and chemical sensors.

Chen-Kai Chang received his $\mathrm{PhD}$ degree in microbiological and biological engineering from the Taiwan University, Taipei, Taiwan. He is currently an assistant professor in the Department of Food Science at Chia Nan University of Pharmacy and Science, Tainan, Taiwan. His research interests include plant cell culture and chemical sensors.

Su-Fen Chou received her PhD degree in agriculture chemistry from the Taiwan University, Taipei, Taiwan. She is currently an associate professor in the Department of Biotechnology, at Chia Nan University of Pharmacy and Science, Tainan, Taiwan. Her research interests include cell culture and chemical sensors.

Hsei-Chen Han received her MS degree in agriculture chemistry from the Chinese culture University, Taipei, Taiwan. He is currently a doctor candidate in the Taiwan University, Taipei, Taiwan. His research interests include life science and chemical sensors.

Chien-Yuan Chen received his PhD degree in life science from National Taiwan University, Taipei, Taiwan and $\mathrm{PhD}$ of engineering from The University of Tokyo, Japan. He is currently a professor in microbiological and biological engineering from the Taiwan University, Taipei, Taiwan. His research interests include life science and chemical sensor. 